\title{
Pseudepigraphie und Verfasserfiktion in frühchristlichen Briefen
}

\author{
Pseudepigraphy and Author Fiction in Early Christian Letters \\ Hrsg. v. Jörg Frey, Jens Herzer, Martina Janßen u. Clare K. Rothschild, u. Mitarb. v. \\ Michaela Engelmann
}

Pseudepigraphie und

Verfasserfiktion in

frühchristlichen Briefen

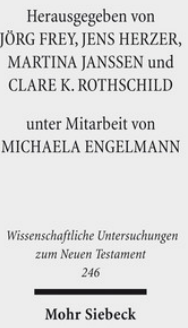

2009. XII, 902 Seiten. WUNT I 246

ISBN 978-3-16-151535-4

DOI 10.1628/978-3-16-151535-4

eBook PDF $159,00 €$

ISBN 978-3-16-150042-8

Leinen $159,00 €$
Versuche der Beurteilung von Pseudepigraphie in der Antike und im Neuen Testament sind zuletzt in den 1960er und 1970er Jahren unternommen worden. In der neutestamentlichen Forschung wurden die aus der Altertumswissenschaft stammenden Anregungen oft einseitig zur generellen Legitimation neutestamentlicher Pseudepigraphie rezipiert, ohne nach einer differenzierten Beurteilung der jeweiligen pseudepigraphischen Fiktion und ihrer Legitimität zu fragen. Angesichts dieser Situation sollen mit dem vorliegenden Band Problematik und Vielfalt der Pseudepigraphie neutestamentlicher Briefe dokumentiert, die neueren Ansätze zusammengefasst und so die Diskussion weiter vorangebracht werden. Es wird dabei eine repräsentative Breite angestrebt, die nicht nur alle im Neuen Testament als pseudepigraphisch beurteilten Briefe (einschließlich des Hebräerbriefes) behandelt, sondern den Kontext antiker und frühjüdischer Pseudepigraphie berücksichtigt. So werden auch die für die Entstehung neutestamentlicher Briefe traditionsgeschichtlich relevanten Bereiche einbezogen, u.a. apokalyptische Literatur, Weisheits- und Testamentenliteratur, apokryphe Schriften sowie der antike Briefroman.

Inhaltsübersicht

Martina Janßen / Jörg Frey: Einführung

I. Frühjüdische Kontexte

Leo G. Perdue: Pseudonymity and Graeco-Roman Rhetoric. Mimesis and the Wisdom of Solomon - Karina Martin Hogan: Pseudepigraphy and the Periodization of History in Jewish Apocalypses - Eibert Tigchelaar: Forms of Pseudepigraphy in the Dead Sea Scrolls

II. Griechisch-römische Kontexte

Wolfgang Speyer: Göttliche und menschliche Verfasserschaft im Altertum - Martina Janßen: Antike (Selbst-)Aussagen über Beweggründe zur Pseudepigraphie - Marco Frenschkowski: Erkannte Pseudepigraphie? Ein Essay über Fiktionalität, Antike und Christentum - Katharina Luchner: Pseudepigraphie und antike Briefromane - Timo Glaser: Erzählung im Fragment. Ein narratologischer Ansatz zur Auslegung pseudepigrapher Briefbücher - Robert Matthew Calhoun: The Letter of Mithridates. A Neglected Item of Ancient Epistolary Theory

III. Frühchristliche Kontexte

Harry Y. Gamble: Pseudonymity and the New Testament Canon - Eve-Marie Becker: Von Paulus zu »Paulus«. Paulinische Pseudepigraphie-Forschung als literaturgeschichtliche Aufgabe - Martin Hüneburg: Paulus versus Paulus. Der Epheserbrief als Korrektur des Kolosserbriefes - Nicole Frank: Der Kolosserbrief und die »Philosophia«. Pseudepigraphie als Spiegel frühchristlicher Auseinandersetzungen um die Auslegung des paulinischen Erbes - Trevor Thompson: A Stone that Still Won't Fit. An Introductory and Editorial Note for Edgar Krentz's »A Stone that Will Not Fit« - Edgar Krentz: A Stone That Will Not Fit. The Non-Pauline Autorship of 2 Thessalonians - Trevor Thompson: As If Genuine. Interpreting the Pseudepigraphic Second Thessalonians - Jens Herzer: Fiktion oder Täuschung? Zur Diskussion über die Pseudepigraphie der Pastoralbriefe - Clare K. Rothschild: Hebrews as a Guide to Reading Romans - Matthias Konradt: »lakobus, der Gerechte«. Erwägungen zur Verfasserfiktion des Jakobusbriefes - Matt Jackson-McCabe: The Politics of Pseudepigraphy and the Letter of James - Karl Matthias Schmidt: Die Stimme des Apostels erheben. Pragmatische Leistungen der Autorenfiktion in den Petrusbriefen - Lutz Doering: Apostle, Co-Elder, and Witness of Suffering. Author Construction and Peter Image in First Peter - Jörg Frey: Autorfiktion und Gegnerbild im Judasbrief und im Zweiten Petrusbrief - Jutta Leonhardt-Balzer: Pseudepigraphie und Gemeinde in den Johannesbriefen - Stefan Krauter: Was ist »schlechte« Pseudepigraphie? Mittel, Wirkung und Intention von Pseudepigraphie in den Epistolae Senecae ad Paulum et Pauli ad Senecam

Nachwort

David E. Aune: Reconceptualizing the Phenomenon of Ancient Pseudepigraphy: An Epilogue

Jörg Frey Geboren 1962; 1996 Promotion; 1998 Habilitation; Professur für neutestamentliche Wissenschaft mit den Schwerpunkten Antikes Judentum und Hermeneutik an der Theologischen Fakultät der Universität Zürich und Research Associate der University of the Free State, Bloemfontein/ZA.

https://orcid.org/0000-0001-6628-8834

Jens Herzer Geboren 1963; 1993 Promotion und 1997 Habilitation an der Humboldt Universität zu Berlin; seit 1999 Professor für Neutestamentliche Wissenschaft mit Schwerpunkt Exegese und Theologie des Neuen Testaments sowie Antikes Judentum an der Theologischen Fakultät der Universität Leipzig.

Martina Janßen ist Pastorin und Lehrbeauftragte an der TU Braunschweig.

Clare K. Rothschild Born 1964; 1986 BA University of California, Berkeley; 1992 MTS Harvard University; 2003 PhD University of Chicago; 2006 postdoctoral fellow Alexander von Humboldt Foundation at Ludwig-Maximilians-Universität München; currently Professor of Scripture, Department of Theology, Lewis University (USA) and Professor Extraordinary, Department 
Ancient Studies at Stellenbosch University (South Africa).

https://orcid.org/0000-0002-6572-8604

Michaela Engelmann Keine aktuellen Daten verfügbar.

Jetzt bestellen:

https://mohrsiebeck.com/buch/pseudepigraphie-und-verfasserfiktion-in-fruehchristlichen-briefen-9783161515354?

no_cache=1

order@mohrsiebeck.com

Telefon: +49 (0)7071-923-17

Telefax: $+49(0) 7071-51104$ 